\title{
Grupo de orientação de mães no contexto de uma clínica-escola ${ }^{1}$
}

\author{
Maria Benedita Lima Pardo ${ }^{2}$ \\ Margarida Maria Silveira Britto de Carvalho \\ Universidade Federal de Sergipe, Aracaju-SE, Brasil
}

\begin{abstract}
Resumo: O ambiente familiar vem merecendo atenção de estudiosos que analisam a influência de diferentes ambientes sociais no desenvolvimento infantil. Elaborou-se uma proposta de grupo de orientação para mães de crianças em fila de espera para atendimento psicoterápico. Os objetivos do presente estudo são descrever as características de funcionamento desse grupo e analisar seus resultados sob a perspectiva dos orientadores do grupo e das próprias mães. Os dados foram coletados em entrevistas iniciais e finais e no decorrer dos encontros. Procedeu-se à análise de conteúdo das informações relacionadas às falas das mães e aos procedimentos de intervenção. Os resultados indicaram estar ocorrendo aumento nos diálogos com os filhos, preocupação em dedicar-lhes mais tempo e a entender seus pontos de vista, busca em estabelecer limites, envolvendo também outras pessoas da família. Tais mudanças revelaram, portanto, alterações no funcionamento do microssistema familiar.
\end{abstract}

Palavras-chave: mães, grupos de apoio, ambientes sociais.

\section{Group of parental education in the context of a school-clinic}

\begin{abstract}
Family has received special attention from scholars who analyze the influence of different social environments in children's development. It was carried out a study with a parent group whose children were waiting for psychotherapy. The aims of this study are to describe the functioning characteristics of such group and analyze their results from the view point of group leaders and mothers themselves. The data was collected from interviews that happened in the beginning and the final processes and throughout the meetings. The content of the information was analyzed concerning mother's opinions and the intervention procedures. The results indicated an increase in the numbers of dialogues with children, preoccupation with dedicating more time to them, understand their points of view and also look forward to establish limits involving other members of the family. Such changes revealed alterations in the familiar microsystem functioning.
\end{abstract}

Keywords: mothers, support groups, social environment.

\section{Grupo de orientación de madres en el contexto de una escuela clínica}

Resumen: Los especialistas que analizan la influencia de los diferentes ambientes sociales en el desarrollo del niño se dedican a estudios en torno del ambiente familiar. En este trabajo, se ha elaborado una propuesta para grupo de orientación a las madres. El objetivo consistió en describir las características de funcionamiento de ese grupo y analizar sus resultados desde el punto de vista de los orientadores y de las madres. Los datos fueron recolectados a través de entrevistas iniciales, finales y durante los encuentros. Se procedió al análisis de contenido de las informaciones relacionadas a los puntos de vista de las madres y a los procedimientos de la intervención. Los resultados revelaron un aumento en los diálogos con los hijos, además de preocupación por dedicarles más tiempo y comprender sus puntos de vista, intentando establecer límites que también involucran a otras personas de la familia. Dichos cambios revelan alteraciones en el microsistema familiar.

Palabras clave: madres, grupos de apoyo, ambientes sociales.

O atendimento do psicólogo necessita ser avaliado em termos da relevância e permanência de seus efeitos positivos para os usuários de seus serviços (Pardo, 1997). Neste trabalho, descrevemos um tipo de atendimento realizado no Serviço de Psicologia Aplicada (SPA), o qual funciona junto ao curso de graduação em Psicologia de uma Universidade pública. No SPA, além de se prestar serviço à população, tem-se, como objetivo, a formação profissional de psicólogos, por meio de

\footnotetext{
${ }^{1}$ Trabalho apresentado no Simpósio Orientação familiar e a prevenção de deficiências na XXXVI Reunião Anual da Sociedade Brasileira de Psicologia realizada em outubro de 2007 em Florianópolis-SC. Este texto foi revisado seguindo Acordo Ortográfico da Língua Portuguesa (1990), em vigor a partir de $1^{\circ}$ de janeiro de 2009 .

${ }^{2}$ Endereço para correspondência:

Maria Benedita Lima Pardo. R. Vila Cristina, 68, apto 301. CEP 49.015-000.

Aracajú-SE, Brasil.E-mail: pardombl@hotmail.com
}

estágios supervisionados.

Uma parte da clientela atendida pelo SPA costuma ser representada por crianças em idade escolar, frequentadoras da primeira etapa do Ensino Fundamental ( $1^{\mathrm{a}}$ a $4^{\mathrm{a}}$ séries $)$, encaminhadas com queixas de dificuldades de aprendizagem e/ou de problemas de comportamento. A partir da queixa apresentada, profissionais e alunos que atuam no SPA iniciam um processo de diagnóstico, visando a caracterizar a existência ou não de problemas, analisar suas características e delinear encaminhamentos para possíveis tratamentos. Essa demanda representa mais de $50 \%$ das solicitações anualmente recebidas pelo SPA (Carvalho, 2007), implicando na existência de fila de espera. Um aspecto preocupante detectado nessa situação é o frequente desconhecimento dos familiares sobre o desenvolvimento infantil, o que, muitas vezes, leva ao rotulamento da criança como incapaz, podendo agravar ainda mais o problema. 
Diante desse quadro, foram formados grupos de orientação de mães com o intuito de fornecer suporte a essas famílias que demandam apoio psicológico e informações a respeito do desenvolvimento infantil.

\section{Modelos de atuação do psicólogo clínico}

Na área de Psicologia Clínica há muitas discussões sobre modelos de atendimento que assegurem benefícios para a clientela, entre os quais podemos citar: rapidez na obtenção de resultados esperados, sua relevância para o cliente e domínio, por parte do cliente, de certos procedimentos que lhe garantam independência para continuar lidando com situações-problemas já conhecidas e para resolver novas situações que se apresentem (Abreu \& Guilhardi, 2008).

O modelo tradicional de atendimento em Psicologia Clínica foi derivado do modelo médico (Ullmann \& Krasner, 1969). Baseia-se na suposição de que os problemas apresentados pelo cliente são sintomas de desordens psicológicas que ocorrem nele mesmo. Concentra-se na interação terapeuta-cliente, em situação de consultório. $\mathrm{Na}$ fase de diagnóstico, o psicólogo coleta dados sobre o caso por meio de entrevistas, de aplicação de testes ou desenvolve observações na própria situação de atendimento. Não considera necessário coletar informações nos ambientes em que a pessoa vive, pois seus focos de análise são os comportamentos apresentados pelo cliente. Tais comportamentos são tomados como indicadores de outro fenômeno que vai se definindo a partir do confronto entre os dados obtidos e a orientação teórica seguida pelo terapeuta. $\mathrm{Na}$ fase de intervenção, o terapeuta elabora um plano de tratamento, com base nas interações que ocorrem entre ele e o cliente, ou propõe situações no consultório que, uma vez vivenciadas pelo cliente, representariam ocasiões para observação de suas dificuldades e apropriada interferência do terapeuta. Não há preocupação em verificar se há relações entre as intervenções realizadas no consultório e alterações que possam estar ocorrendo nos ambientes em que o cliente vive, em termos de sua forma de agir, de alterações que ele possa estar introduzindo nesses ambientes e como o próprio ambiente reage a essas modificações (Rangé, 2001). Portanto, nesta etapa, o principal indicador da melhora do cliente consiste em seus relatos verbais ou das pessoas com quem ele convive, como é o caso do tratamento de crianças. Assim, a atuação profissional, de acordo com o modelo médico, concentra-se, de modo especial, na interação terapeuta-cliente.

A partir da reflexão sobre críticas, foi proposto o modelo psicológico de intervenção, segundo o qual as dificuldades relatadas pelo cliente em suas queixas estão relacionadas a interações mantidas com seus ambientes e a estímulos aí presentes. À medida que as relações com o ambiente são apreendidas, também podem ser modificadas, no sentido de melhor viabilizarem a adequação da pessoa ao seu ambiente e vice-versa. De acordo com esse modelo, desde a fase de diagnóstico, o psicólogo preocupa-se em coletar dados não apenas no consultório, com instrumentos padronizados, mas, também, nos diferentes ambientes onde surgem os comportamentos-queixa. No decorrer da intervenção, o foco do atendimento estará voltado para a orientação ao cliente, visando a discriminação de estímulos que poderiam estar provocando seu mal-estar e na discussão de como ele poderia lidar com tais estímulos de modo a eliminálos, neutralizá-los ou buscando formas alternativas de impedir que os mesmos afetem seu modo de agir.

O modelo psicológico de intervenção, além de ampliar o ambiente da terapia para além das quatro paredes do consultório, permite ao terapeuta obter informações e relatos significativos de pessoas que convivem com o cliente nos ambientes onde os problemas estão surgindo. Esse modelo de atendimento visa ampliar os resultados das intervenções. No caso de crianças em idade escolar, essas pessoas podem ser os pais, irmãos, membros da família extensa e professores.

Com base nos pressupostos do modelo psicológico de atendimento, Tharp e Wetzel (1969) propuseram um modelo de intervenção triádico, segundo o qual a mudança terapêutica não está baseada apenas na interação do cliente com o terapeuta. O modelo triádico preconiza que uma pessoa significativa para o cliente participe ativamente de todo o trabalho realizado. Essa pessoa é denominada mediadora e pode assumir diversas funções no processo, desde aplicar intervenções recomendadas pelo terapeuta até participar da escolha do comportamento a ser modificado; também atua no planejamento e na aplicação de intervenções. O terapeuta, por sua vez, tem função colaborativa no sentido de estimular, tanto o cliente como as outras pessoas envolvidas no tratamento, a proporem e a desenvolverem alterações que considerem importantes para a melhoria do bem estar de todos, em seus ambientes ou em seus modos de agir.

\section{Atendimento a famílias: tendências atuais}

Levantamento sobre os enfoques relacionados à orientação de pais e famílias (Dessen \& Silva, 2004; McMahon, 1999) mostra que ao longo do tempo foram atribuídos distintos valores à importância dos diversos componentes envolvidos com esses programas. Inicialmente foi conferido maior valor à criança e aos problemas a ela inerentes. Nesse contexto, os pais deveriam assumir o papel de extensão do profissional para desenvolver o trabalho de minorar esses problemas. Por outro lado, o profissional considerava-se habilitado para propor os tipos de intervenção necessária.

O próprio avanço dos estudos em psicologia do desenvolvimento evidenciou que o problema não residia apenas, ou em sua maior parte, na criança, mas nas relações que se estabeleciam entre ela e as pessoas de seu ambiente e também no modo como a situação problema era percebida pelos envolvidos (Dessen \& Polonia, 2007). Neste momento, a importância de se considerar os pais como agentes ativos foi ressaltada, havendo, portanto, necessidade de redefinir seus papéis neste contexto. Assim, os pais passaram a ser colaboradores (Buswell \& Schaffner, 2002) nas situações analisadas e o profissional assumiu um papel de coadjuvante. 
Outro fator de grande importância a ser considerado nessa mudança de enfoque da orientação familiar consiste nas rápidas modificações pelas quais passa a nossa sociedade, colocando desafios cotidianos para a educação de filhos. Uma delas se refere à diversidade de configurações que a própria família tem assumido, como, por exemplo, família de um só genitor, família composta por pais homossexuais, família em que avós assumem a educação da criança e na qual nenhum dos pais se encontra presente. Outra mudança diz respeito à diversidade de valores referentes às relações humanas com a qual a família entra em contato (Campbell \& Palm, 2004), seja pela divulgação de padrões de interação veiculados pelos meios de comunicação de massa, seja pelo contato direto ou indireto com diferentes ambientes, como a escola ou grupos de amigos que a criança passa a frequentar.

Nesse contexto de mudanças, nem os pais, nem os profissionais, por si só, conseguem elaborar respostas para os desafios impostos pelo processo de educação de filhos. As soluções para os problemas precisam ser construídas (Brooks \& Brooks, 2004) em cooperação entre profissionais, familiares e as próprias crianças. Assim, o que se impõe é a necessidade de criar situações em que pais, filhos e profissionais possam dialogar, trocar experiências, visando apoio mútuo para a tomada de decisões quanto aos caminhos e atitudes a serem adotadas no processo de educação de filhos no qual se encontram envolvidos. À medida que tais apoios estejam disponíveis, por iniciativa de profissionais ou de instituições, criam-se condições para fornecer orientações, informações e esclarecer dúvidas das famílias no que se refere à educação de filhos, assim como para contribuir com a prevenção de problemas que possam surgir.

Desse modo, a evolução dos estudos na área de atendimento a famílias tem mostrado uma tendência em considerar seu funcionamento a partir de uma concepção ecossistêmica. Nessa concepção, a família é considerada como um microssistema inserido em sistemas "maiores", tal como o macrossistema.

Bronfenbrenner $(1989,1994 / 1996)$ propõe o modelo bioecológico como base para o estudo do desenvolvimento humano, sendo que o mesmo tem sido aplicado a estudos que envolvem o trabalho com famílias (Araújo, 2001; Colnago, 2000; Inforsato, 2001;). Em consonância com o modelo bioecológico, este trabalho propõe o atendimento a grupo de pais cujas crianças passaram pela triagem do SPA e já estavam em atendimento ou em fila de espera para iniciar seu tratamento. Para tanto, partiuse da análise de fatores presentes nos microssistemas em que a criança estava inserida, em especial, sua casa. Entretanto, não se deixou de considerar outros ambientes, tal como a escola, sempre que informações a eles relacionadas se mostrassem relevantes no decorrer das análises sobre as questões colocadas pela família. Também se procurou dar espaço para a identificação e discussão sobre modos de pensar e valores quanto à educação (influências do macrossistema) trazidos pelos participantes do grupo.

O trabalho também adotou o modelo triádico de atuação do profissional, propondo o desenvolvimento de atividades em parceria com membros da família da criança. Nesse sentido, procurou envolver os familiares em tomadas de decisão nas diferentes etapas do trabalho, considerando suas opiniões e necessidades. Por esta mesma razão, optou-se por denominar o programa como "grupo de orientação a pais", pois esperava-se estimular sua participação ativa em todas as etapas do processo, visando desenvolver habilidades que lhes viabilizassem maior adequação e independência no modo de se relacionarem com seu filho. Assim, o funcionamento do grupo não se caracterizou como grupo terapêutico e, sim, como educativo (Campbell \& Palm, 2004). Nesse processo de orientação, procurou-se envolver os pais e/ou outras pessoas significativas (avó, tios) no ambiente em que a criança vivia. Entretanto, foram as mães que, efetivamente, participaram da constituição do grupo.

Nesse contexto, o objetivo desse estudo é descrever as características de funcionamento de um grupo de orientação de mães e analisar seus resultados do ponto de vista de seus orientadores e das próprias mães.

\section{Método}

\section{Participantes}

O grupo foi composto por quatro mães, com idades entre 30 e 58 anos, renda familiar de até dois salários mínimos e nível de escolaridade correspondente ao Ensino Fundamental.

\section{Instrumentos}

Foi utilizado um protocolo de entrevista aplicado às participantes antes do início do grupo e após seu encerramento, com o intuito de levantar as características dos problemas que as haviam levado a frequentar o grupo e como as mães avaliavam tais problemas. Sua aplicação nesses dois momentos possibilitava uma avaliação qualitativa das mudanças ocorridas.

Também foram utilizados roteiros para condução dos encontros. Tais roteiros foram construídos a partir do levantamento inicial de interesses realizado no grupo e de outras necessidades que iam surgindo no decorrer de seu funcionamento.

\section{Considerações éticas}

Foi solicitado às mães que assinassem o Termo de Consentimento Livre e Esclarecido, que garantia sua participação voluntária no grupo, sua saída do mesmo em qualquer momento em que desejassem e a viabilidade de divulgação dos resultados respeitando-se a guarda de sigilo quanto às suas identidades.

\section{Procedimentos}

Divulgação do grupo de orientação

A divulgação da realização do grupo de orientação foi feita por telefone ou carta-convite, a partir de levantamento 
realizado nos arquivos de casos de crianças em atendimento ou que se encontravam em lista de espera do SPA. Foi também afixado cartaz na sala de espera do SPA, divulgando a realização do grupo e enviado aviso aos supervisores da área clínica. Toda divulgação era extensiva aos pais ou cuidadores das crianças. Entretanto, apenas mães e uma avó retornaram, sendo que a última frequentou somente a primeira sessão do grupo.

\section{Entrevista inicial}

Com as mães que manifestaram interesse em participar do grupo foi realizada, individualmente, uma entrevista inicial na qual se procedeu a um primeiro levantamento sobre os motivos que as tinham trazido ao SPA e suas expectativas em relação ao grupo de orientação. Foi solicitado que assinassem um Termo de Consentimento Livre e Esclarecido. A partir de suas disponibilidades, foram definidos dias e horários para os encontros do grupo.

\section{Descrição dos encontros}

Foram realizados oito encontros, sendo um por semana, com duração de uma hora e meia cada. Eles eram coordenados por duas estagiárias, alunas do $9^{\circ}$ e $10^{\circ}$ semestres do curso de graduação em Psicologia, que se encontravam sob supervisão de professoras da área de Psicologia Clínica, autoras deste trabalho.

\section{A constituição do grupo}

Inicialmente, fez-se uma exposição sobre os objetivos do programa de orientação e, a seguir, foram elaboradas, juntamente com as mães, algumas regras de funcionamento a serem respeitadas: direito à manifestação de cada um e o respeito à opinião do outro, manutenção do sigilo em relação aos problemas ali tratados, compromisso com a presença e horário. Foi também esclarecido que o grupo não tinha finalidade terapêutica, mas sim função de apoio, no sentido de orientar sobre as questões que haviam levado aquelas mães a procurar o SPA. A seguir, foi realizado um levantamento de problemas e situações que gostariam de abordar. A partir desse levantamento, foram planejados os próximos encontros.

\section{Os encontros}

A cada encontro, as mães eram estimuladas a relatar situações cotidianas sobre as quais gostariam de obter algum esclarecimento, visando superar dificuldades de relacionamento ou de tomada de decisão. Paralelamente à discussão destas situações, eram apresentadas informações, em linguagem coloquial, a respeito dos princípios do controle do comportamento, tais como reforçamento positivo, negativo, punição e suas consequências sobre os comportamentos desejáveis e indesejáveis. Também eram apresentadas informações sobre características das fases do desenvolvimento infantil e levantadas sugestões sobre formas de agir que se mostravam mais apropriadas às situações colocadas pelas próprias mães. Desse modo, eram obtidas opiniões e análises das próprias mães sobre as situações apresentadas por cada uma delas, o que facilitava o debate e a aceitação das colocações.

Durante as sessões, também foram utilizadas atividades vivenciais com objetivo de auxiliar a análise e a avaliação de situações de relacionamento. Solicitou-se, por exemplo, que, em duplas, as mães relatassem às suas parceiras como se percebiam no papel de mãe. A seguir, cada pessoa da dupla relatava ao grupo o que sua companheira lhe havia revelado. Nesse momento, as demais mães tinham oportunidade de se manifestar $\mathrm{e}$, frequentemente, relacionavam os depoimentos a aspectos de suas próprias vivências, fornecendo, assim, espontaneamente, outras interpretações sobre os depoimentos ou mesmo sugestões de outras formas de agir ou, ainda, de como encarar a situação relatada.

Foi realizada uma sessão de brincadeiras em que as mães trouxeram seus filhos para que, juntos, desenvolvessem atividades lúdicas. Tal sessão foi muito importante para se observar diretamente aspectos da interação mãe-filho. Discutiu-se sobre a brincadeira como um momento importante para esta interação, por possibilitar aproximação afetiva e troca de experiências. Enfatizou-se que esse momento devia ser prazeroso, isento de críticas e oferecer oportunidade para expressar elogios e afeto.

\section{Entrevista final}

Ao término dos oito encontros, procedeu-se a uma entrevista individual com as mães visando coletar dados sobre as contribuições do grupo de orientação para o filho, para a família e para ela mesma. Também foram levantadas as dificuldades durante os encontros e solicitadas sugestões para melhoria do funcionamento de futuros grupos.

\section{Análise dos dados}

Os dados foram registrados pelas estagiárias em termos de relatórios descritivos de cada sessão de atendimento ao grupo, os quais eram lidos pelas supervisoras e utilizados como base para condução do grupo e fonte de informações para descrição dos resultados da pesquisa. Buscou-se extrair os resultados mais relevantes relativos às colocações das mães e aos procedimentos de intervenção que foram utilizados, mediante análise de conteúdo (Bardin, 2004). Para tanto, após leitura dos registros das sessões, buscou-se extrair e sistematizar as informações referentes às formas de agir da criança, da própria participante e eventuais mudanças percebidas nesses comportamentos, além de atentar para relatos sobre condições consideradas favoráveis ou não, presentes no ambiente em que mãe e criança conviviam. Também foram analisados os relatos relacionados ao funcionamento do grupo. 


\section{Resultados e Discussão}

Os resultados foram organizados em forma de casos, com base nos resultados obtidos nos oito encontros do grupo.

\section{Caso M1}

Esta mãe havia procurado o SPA pelo fato de seu filho, de oito anos, estar apresentando dificuldade de aprendizagem. Relatou ter outros dois filhos: uma menina de 12 anos e outro menino, de dez anos. Contou que sentiu muita dificuldade quando seu segundo filho nasceu, pois ele tinha Síndrome de Down e ela nada sabia sobre a síndrome. Porém, disse que o nascimento desse filho mudou sua visão de mundo. Considerou-se rígida no papel de mãe e sentia-se cobrada pela família para que mudasse de postura. Esse aspecto de seu depoimento também esteve presente nas falas de outras mães - a cobrança de ser "mãe" ideal - o que deu margem à discussão sobre a imposição da perfeição como um valor presente nas famílias e na sociedade e ao questionamento desse valor. Este tema também possibilitou colocações sobre a função do grupo de orientação que estaria discutindo o papel dos pais, não em termos de regras a serem seguidas, mas de discussões sobre aspectos do comportamento e desenvolvimento infantil que poderiam ser úteis para a educação de seus filhos e pudessem diminuir conflitos e esclarecer dúvidas. Na sessão em que foram desenvolvidas as brincadeiras, essa mãe interagiu e brincou, cooperativamente, com seu filho, incentivando-o e elogiando suas produções (ele escolheu brincar com um jogo de construção). M1 considerou a brincadeira como um momento importante para ficar próxima a seu filho e relatou que as discussões em grupo, por favorecerem o debate, a ajudaram a esclarecer dúvidas quanto à educação de filhos. Em seu depoimento final, disse: "Aprendi a conversar com meu filho, vi o lado dos outros, vi a dificuldade...Tiramos proveito, vimos que os outros têm dificuldades...”. Também se referiu ao fato de estar mais atenta ao ponto de vista dos outros. As palavras escolhidas, ao final, para resumir sua experiência de participação no grupo foram: "amizade, dúvida, descoberta e esperança".

\section{Caso M2}

Esta mãe trouxe a filha de dez anos para tratamento devido a problemas emocionais relacionados à separação dos pais e pelo fato de a mesma precisar de limites. Esta mãe percebia-se como protetora da filha, embora procurasse também fornecer incentivos para que se tornasse independente. Considerou-se muito preocupada com o futuro da filha e, assim, cobrava muito seus desempenhos. Ela própria avaliou estar emocionalmente instável, o que poderia estar prejudicando seu relacionamento com a filha, questionando, inclusive, se não era esse o problema a ser enfrentado. Em relação às situações discutidas, revelou sentir dificuldades para impor limites à filha, pois havia parentes, com os quais moravam, em especial os avós e um tio da criança, que cediam às suas vontades. Enfatizou que buscava conversar com a criança de forma a evitar conflitos. Na situação de brincadeira, trabalhou paralelamente à sua filha na confecção de desenho; não elogiou a atividade, mas afirmou que procurava brincar quando havia tempo disponível; a menina, por sua vez, confirmou declarando que "mamãe brinca comigo quando não está estressada". Relatou que o grupo a ajudou a ser mais calma, a propor regras e sustentá-las e considerou que sua filha mudou o comportamento devido às suas próprias mudanças. Para ela, o programa de orientação trouxe mais segurança para suas ações e benefícios também para o ambiente de casa e educação da filha. Declarou: "Passei a ouvir mais minha filha e estou tentando compreende-la. Foi muito importante perceber que outras mães passam por situações iguais". Suas palavras para caracterizar a experiência no grupo foram: "luz, compartilhar, auto-estima e otimismo".

\section{Caso M3}

Segundo esta mãe, sua filha de seis anos era teimosa, muito agitada e apresentava problemas na escola em relação aos estudos. Essa criança foi adotada em um momento em que seus outros quatro filhos, homens, já estavam crescidos. Gostaria de aprender a lidar com a filha sobre os assuntos da escola, fazê-la estudar em casa, saber como conseguir ensiná-la e agir diante da teimosia.

Considerava que, em seu papel, não poderia rejeitá-la, pois, nesse caso, a criança sentir-se-ia diferente. Discutiu sua dificuldade em impor limites, mas, ao longo dos encontros, revelou estar melhorando seu controle sobre a criança e, inclusive, transmitindo as informações ao pai para que pudesse agir de modo consoante. Relatou ter tido uma conversa séria com o marido para que a apoiasse nas decisões em relação à menina.

$\mathrm{Na}$ situação de brincadeira, iniciou um desenho junto com a filha e demonstrou comportamento autoritário, dizendo o que a filha deveria desenhar; chegou, inclusive, a segurar sua mão para que fizesse o desenho. Ao final dessa sessão, a filha apresentou comportamento de rebeldia, pois não deixava os brinquedos, apesar da solicitação da mãe para que o fizesse. Diante da insistência, atirou o brinquedo ao chão. A mãe considerou que a situação de brincadeira foi importante para evidenciar que deveria dedicar mais tempo à filha. Segundo ela, o grupo possibilitou que notasse haver casos piores que o da sua filha, incentivando-a a ser mais paciente e a dialogar mais com a criança. Suas palavras para caracterizar a experiência no grupo foram: "solidão, ajuda e fé".

\section{Caso M4}

Esta mãe trouxe seu filho de oito anos, com diagnóstico de hiperatividade e acompanhamento de psiquiatra. A criança já havia feito tratamento psicológico e estava retornando. Segundo ela, o filho também era agressivo, principalmente na hora de fazer a lição. Entretanto, relatou uma série de aspectos positivos 
do mesmo, tais como, ser carinhoso, gostar de ajudar. Disse que sempre procurava elogiar a letra do filho e o incentivava a continuar melhorando. Expôs sua dificuldade em assumir o papel de mãe, pois teve dificuldades em aceitar a gestação. Relatou que a avó materna e o tio das crianças (seu irmão) assumiam a autoridade perante seu filho. Declarou: "Às vezes sinto como se meu filho fosse meu irmão".

Na situação de brincadeira com o filho escolheu, por ele, os brinquedos, competiu no dominó e trapaceou no jogo de pega-varetas, comportando-se como se fosse outra criança e demonstrando necessidade de ganhar. Também ficou evidente a dificuldade em ensinar as regras do jogo de damas: determinava que a criança escolhesse uma peça e dizia as possíveis jogadas, demonstrando impaciência. Revelou, portanto, sua dificuldade em assumir o papel de mãe.

Nas discussões, verbalizou considerar difícil estabelecer limites e que, muitas vezes, gritava e batia para obter o comportamento desejado. Revelou também que as discussões do grupo a ajudaram a mudar um pouco esses comportamentos. Quanto à melhora observada em seu filho, atribuiu-a aos remédios que ele tomava. Entretanto, considerou que o grupo a ajudou a perceber a importância de dedicar mais tempo ao filho, impor limites e substituir o grito pelo diálogo. Suas palavras para caracterizar a experiência no grupo foram: "perdão, orgulho, amor, angústia".

\section{Avaliação dos orientadores do grupo}

Os resultados apresentados revelam que há pontos em comum nas mudanças relatadas pelas mães, tais como, aumento de diálogos com os filhos, preocupação em lhes dedicar mais tempo, em compreender seus pontos de vista e buscar impor limites. Também houve relato de envolvimento de outras pessoas da família, como no caso M3, do apoio recebido do pai. Esses relatos sinalizam para alterações no funcionamento do microssistema familiar e estão consonantes com resultados relatados por Bolsoni-Silva (2007), segundo a qual o aumento de práticas parentais positivas tem sido relacionado aos trabalhos de orientação de pais ou responsáveis.

Os depoimentos também revelaram a importância da troca de informações no grupo uma vez que os relatos de situações, por diferentes participantes, possibilitaram novas discussões. Essa troca de experiências permitiu ainda o compartilhamento de exemplos e contra-exemplos sobre formas de agir e o surgimento de novos parâmetros para avaliar as dificuldades advindas dos problemas que as estavam afligindo, implicando, muitas vezes, na relativização do grau de dificuldade. Resultados semelhantes foram obtidos por Rolfsen e Martinez (2008), em um programa psicopedagógico de orientação a pais (PPOP).

Todas essas alterações observadas não significam que as concepções sobre suas funções de mãe e sobre os papéis de seus filhos no processo educativo tenham sido completamente alteradas. Foi possível observar que o grupo desencadeou um processo de mudança, em pleno andamento, quando suas atividades se encerraram. Exemplo disso foi o depoimento de M4 que, na avaliação final, relatou várias mudanças em seu comportamento e também no de seu filho, embora, na sessão anterior, as houvesse atribuído aos medicamentos que a criança estava tomando. É possível que tal concepção ainda fizesse sentido para essa mãe.

O mesmo pode-se dizer sobre a noção da localização do problema, que sempre foi atribuído à criança, no início do grupo. Foi realizado um trabalho visando mostrar a interdependência dos fatores pertinentes aos diversos ambientes frequentados pela criança, os quais poderiam, ainda que indiretamente, influenciá-la. Acredita-se que essa nova concepção também estivesse em processo de maturação para essas mães.

O modo de pensar a origem de um problema psicológico e o papel de "ser mãe" e "ser filho" tem suas raízes em concepções e valores que as pessoas trazem de sua educação e de vivências anteriores, em relação às quais ocorre a influência de valores culturais, presentes no macrossistema (Bronfenbrenner, 1994/1996). Campbell e Palm (2004) também alertam para a influência dos valores culturais no grupo, em relação aos quais o orientador deve agir com cautela. Nesse sentido, a modificação desses modos de pensar requer um processo que, muitas vezes, é lento e gradual e nem sempre surge de modo imediato. Assim, sugere-se a realização de sessões de follow-up, de forma a acompanhar esses processos de modificação após o encerramento do grupo (Colnago, 2000).

A sessão de brincadeiras foi importante para se observar diretamente aspectos do relacionamento mãe-filho e possibilitar valiosas informações que passaram a ser utilizadas nas sessões subsequentes. Segundo as mães, tal sessão facilitou a percepção de aspectos do seu relacionamento com os filhos e a tomada de consciência da necessidade de dedicar mais tempo a eles. Por esta razão, sugere-se ampliar o número dessas sessões, o que está de acordo com a proposta de Campbell e Palm (2004).

\section{Avaliação do funcionamento do grupo pelas mães}

De modo semelhante a Rolfsen e Martinez (2008), neste trabalho também foi solicitado que as participantes avaliassem as contribuições e os aspectos negativos relacionados ao funcionamento do grupo e à sua participação no mesmo. As mães avaliaram positivamente sua participação e os resultados obtidos. Todas relataram mudanças em si mesmas, assim como tornar-se mais calma, procurar observar mais a criança. Também foram relatadas mudanças no que se refere à forma de agir com os filhos, procurando conviver mais com a criança, estabelecendo regras, conversando com os pais e envolvendoos neste processo.

Mesmo quando os relatos sobre si mesma envolviam problemas, como os de M2 e M4, essas colocações no grupo já representavam um avanço na percepção da situação que estavam vivenciando e sua repercussão no relacionamento com a criança. Assim, M2 hipotetizou que sua ansiedade poderia estar 
prejudicando o relacionamento com a filha. De certo modo, colocações desse tipo envolviam a concepção do que é ser "uma boa mãe". Segundo Campbell e Palm (2004), a orientação de pais em grupo pode ser um instrumento poderoso para que aprendam sobre as crenças relacionadas a seus diferentes comportamentos e compartilhem sentimentos honestos sobre "ser pai".

$\mathrm{Na}$ entrevista final, as mães relataram que os problemas que as trouxeram ao SPA ainda persistiam, mas o grupo possibilitou melhora no relacionamento com os filhos, tendo ajudado a amenizar certas áreas de atrito nos relacionamentos familiares.

Quanto ao funcionamento do grupo, não encontraram dificuldades e sugeriram aumento do número de participantes, de encontros e de sessões com os filhos, além de ampliação dos assuntos abordados.

\section{Considerações finais}

Este trabalho adotou duas abordagens para o desenvolvimento do grupo de mães: a abordagem bioecológica, de Bronfenbrenner (1989), e a da psicologia comportamental (Skinner, 1967). É interessante analisar como se deu essa utilização.

Considerando a complexidade das relações mães-filhos, a abordagem bioecológica (Bronfenbrenner, 1989) favoreceu uma visão abrangente quanto à identificação de possíveis fatores que poderiam estar relacionados aos comportamentos das crianças. Neste grupo, especificamente, as queixas e relatos das mães estiveram mais direcionados para o ambiente da família em casa, um microssistema importante. Assim, buscou-se estimulá-las a estabelecer relações entre as ações das pessoas presentes nesses ambientes e alterações observadas no comportamento da criança. Segundo esta linha de trabalho, deve-se também destacar que alguns dos relatos das mães, tal como foram ilustrados na seção de Resultados, revelavam que as mesmas passavam a se perceber como parte do ambiente da criança e, consequentemente, manifestavam certo alívio ao relatarem mudanças de seu próprio comportamento.

Por outro lado, quando se analisavam situações específicas e como poderiam agir diante delas, foi de grande utilidade a adoção de princípios da psicologia comportamental para orientar as discussões, pois a mesma fornece explicações de fácil compreensão e aplicabilidade no cotidiano. Assim, a partir de uma linguagem acessível às mães, discutia-se sobre a utilização de reforçadores e retirada de estímulos aversivos. As mães eram incentivadas a experimentar mudanças nas formas de agir em seus ambientes e, ao relatarem tais mudanças, criavam-se oportunidades para se comparar as vantagens dos reforçadores positivos em relação aos aversivos. Esse tipo de relato costumava vir acompanhado de manifestações de satisfação, indicando aceitação do princípio por parte das mães.

Campbell e Palm (2004) ressaltam que os pais se preocupam profundamente com suas crianças e desejam ser bons pais. Essa preocupação foi observada no grupo de mães, pois, apesar de seus relatos sobre incongruências ou inadequações na condução da educação dos filhos, as mães apresentavam postura de abertura em relação às mudanças e à preocupação em acertar mais. Nesse sentido, os ganhos do grupo podem ser analisados do ponto de vista pessoal das próprias mães ao se sentirem mais satisfeitas com elas mesmas e em relação a alterações no ambiente familiar.

\section{Referências}

Abreu, C. N., \& Guilhardi, H. J. (2008). Introdução. In C. N. Abreu \& H. J. Guilhardi (Orgs.), Terapia comportamental e cognitivo-comportamental: Práticas clínicas (pp. XVXVI). São Paulo: Roca.

Araújo, E. A. C. (2001). Programa de orientação de mães para integração social de adultos portadores de deficiência mental. Tese de doutorado não publicada, Universidade Federal de São Carlos, São Carlos, SP.

Bardin, L. (2004). Análise de conteúdo (3a ed.). Lisboa: Edições 70.

Bolsoni-Silva, A. T. (2007). Intervenção em grupo para pais: Descrição de procedimento. Temas em Psicologia, 15, 217-235.

Bronfenbrenner, U. (1989). Ecological systems theory. Annals of Child Development, 6, 187-249.

Bronfenbrenner, U. (1996). A ecologia do desenvolvimento humano: Experimentos naturais e planejados (M. A. V. Veronese, Trad.). Porto Alegre: Artes Médicas. (Original publicado em 1994)

Brooks, M. G., \& Brooks, J. G. (2004). The courage to be constructivist. In A. S. Canestrari \& B. A. Marlowe (Eds.), Educacional foundations: An anthology of critical readings (pp. 184-194). California: Sage Publications Inc.

Buswell, B. E., \& Schaffner, C. B. (2002). Families as a creative and resourceful collaborators in inclusive schooling. In R. A. Villa \& A. I. Nervin (Eds.), Creativity and collaborative learning: The practical guide to empowering students, teachers, and families (pp. 13-21). Baltimore, USA: Brookes Publishing Co.

Campbell, D., \& Palm, G.F. (2004) Group parent education: Promoting parent learning and support. California: Sage Publications.

Carvalho, M. M. S. B. (2007). Relatório técnico da Coordenação do Serviço de Psicologia Aplicada da Universidade Federal de Sergipe (Biênio 2005-2007). São Cristóvão, SE: Departamento de Psicologia, UFS.

Colnago, N. A. S. (2000). Orientação para pais de crianças com Sindrome de Down: Elaborando e testando um programa de intervenção. Tese de doutorado não publicada, Universidade de São Paulo, Ribeirão Preto, SP.

Dessen, M. A., \& Silva, N. L. P. (2004). A família e os programas de intervenção: Tendências atuais. In E. G. Mendes, M. A. Almeida, \& L. C. A. Willams (Orgs.), Temas em educação especial: Avanços recentes (pp. 179-187). São Carlos, SP: EduFSCAR. 
Dessen, M. A., \& Polônia, A. C. (2007). A família e a escola como contextos de desenvolvimento humano. Paidéia (Ribeirão Preto), 17, 21-32.

Inforsato, F. A. F. (2001). Interação da escola e a família: Considerações a partir de uma abordagem ecológica. Tese de doutorado não publicada, Universidade Estadual Paulista, Araraquara, SP.

McMahon, R. J. (1999). Treinamento de pais. In V. E. Caballo (Org.), Manual de técnicas de terapia e modificação do comportamento (M. D. Claudino, Trad., pp. 399-424). São Paulo: Santos Livraria Editora. (Original publicado em 1996)

Pardo, M. B. L. (1997). Princípios da educação: Planejamento do ensino. Ribeirão Preto, SP: Culto à Ciência.

Rangé, B. (2001). Psicoterapia comportamental. In B. Rangé (Org.), Psicoterapia comportamental e cognitiva: Pesquisa, prática, aplicações e problemas (pp. 35-42). Campinas, SP: Livro Pleno.

Rolfsen, A. B., \& Martinez, C. M. S. (2008). Programa de intervenção para pais de crianças com dificuldades de aprendizagem: Um estudo preliminar. Paidéia (Ribeirão Preto), 18, 175-188.

Skinner, B. F. (1967). Ciência e comportamento humano (J. C. Todorov \& R. Azzi, Trad.). Brasília: EdUnB. (Original publicado em 1953)

Tharp, R. G., \& Wetzel, R. J. (1969). Behavior modification in the natural environment. New York: Academic Press.

Ullmann, L. P., \& Krasner, L. (1969). A psychological approach to abnormal behavior. Englewoods Clifts, NJ: PrenticeHall.

Maria Benedita Lima Pardo é Professora Adjunta do Departamento de Psicologia da Universidade Federal de Sergipe.

Margarida Maria Silveira Britto de Carvalho é Professora Assistente do Departamento de Psicologia da Universidade Federal de Sergipe.

Recebido: 28/03/2009

$1^{a}$ revisão: $26 / 10 / 2009$

$2^{a}$ revisão: $24 / 04 / 2010$

Aceite final: 29/05/2010 